\title{
Communication \\ Determining Robotic Assistance for Inclusive Workplaces for People with Disabilities
}

\author{
Elodie Hüsing *, Carlo Weidemann, Michael Lorenz, Burkhard Corves (D) and Mathias Hüsing \\ Institute of Mechanism Theory, Machine Dynamics and Robotics, RWTH Aachen University, \\ 52062 Aachen, Germany; weidemann@igmr.rwth-aachen.de (C.W.); lorenz@igmr.rwth-aachen.de (M.L.); \\ corves@igmr.rwth-aachen.de (B.C.); huesing@igmr.rwth-aachen.de (M.H.) \\ * Correspondence: huesinge@igmr.rwth-aachen.de
}

check for updates

Citation: Hüsing, E.; Weidemann, C. Lorenz, M.; Corves, B.; Hüsing, M. Determining Robotic Assistance for Inclusive Workplaces for People with Disabilities. Robotics 2021, 10, 44. https://doi.org/10.3390/ robotics 10010044

Received: 19 January 2021

Accepted: 3 March 2021

Published: 5 March 2021

Publisher's Note: MDPI stays neutral with regard to jurisdictional claims in published maps and institutional affiliations.

Copyright: (C) 2021 by the authors. Licensee MDPI, Basel, Switzerland. This article is an open access article distributed under the terms and conditions of the Creative Commons Attribution (CC BY) license (https:// creativecommons.org/licenses/by/ $4.0 /)$.

\begin{abstract}
Human-robot collaboration (HRC) provides the opportunity to enhance the physical abilities of severely and multiply disabled people thus allowing them to work in industrial workplaces on the primary labour market. In order to assist this target group optimally, the collaborative robot has to support them based on their individual capabilities. Therefore, the knowledge about the amount of required assistance is a central aspect for the design and programming of HRC workplaces. The paper introduces a new method that bases the task allocation on the individual capabilities of a person. The method obtains human capabilities on the one hand and the process requirements on the other. In the following step, these two profiles are compared and the workload of the human is acquired. This determines the amount of support or assistance, which should be provided by a robot capable of HRC. In the end, the profile comparison of an anonymized participant and the concept of the human-robot workplace is presented.
\end{abstract}

Keywords: human-robot collaboration (HRC); integration of people with disabilities into the working life (IMBA); method time measurement (MTM); inclusive workplaces

\section{Introduction}

People with disabilities often work beneath their capabilities inducing a dissatisfaction with their occupation, as they feel a lack of self-fulfillment. The project "Next-GenerationDevelop inclusive work with flexible robot solutions" has the goal of supporting and enhancing the individual work capabilities through innovative technology. In consequence, people with disabilities will be considered a part of the primary labour market and will be recognized as valuable members of the working community and society. To reach this goal, industrial workplaces must be adapted individually according to the physical and cognitive abilities of disabled people. The idea is to implement human-robot collaboration (HRC) into workplaces. The main purpose of the collaborative robot is to support the human, enabling them to accomplish work tasks regardless of their physical impairments. HRC is introduced as a new assistive technology for people with disabilities to provide physical assistance. An assistive technology is only helpful if it is adapted to the individual's needs. Therefore, task allocation between humans and robots is a central aspect for the design and programming process of the HRC workplace. For people with disabilities the allocation needs to be based on their individual capabilities. Consequently, a method is required to identify the workload of tasks, in which a particular person might be overloaded and needs to be assisted and supported by a collaborative robot.

The required method is aimed in particular for people with musculo-skeletal disorders that influence motor skills, coordination and/or muscle movements. On the other hand, the target group posses good hearing, vision and speech comprehension. To take the requirements of the general labor market into account, further abilities must nevertheless be assumed. These are giving goal-oriented instructions or working in a goal-oriented manner. Further skills are implementation of learned knowledge, orientation in time and 
place as well as the ability to respect work safety measures.

Based on Fitts' list [1], the capabilities of machines are speed, power, computation, replication, simultaneous operations and short term memory. Additionally, robots are kown for their accuracy, endurance and low quality variations in manufactured products. Dependent on the attached robot equipment, a robot has added capabilities. For example, vision systems add the possibility to recognize and to percept the sorroundig world. Force sensors can detect contacts or control process forces and capacitive sensor skins are able to contactlessly detect collisions with other objects.

An instrument for occupational rehabilitation and integration is the Integration of People with Disabilities into the Working Life $(I M B A)$ method. The respective method documents and compares workplace requirements and individual human capabilities based on standardized motion characteristics and further aspects of working routines. By means of comparison, the workload of a particular person is identified [2]. Even though the IMBA method provides a detailed determination of individual workloads, it is not suited for the individual capability-based task allocation in this project. The reason for this is that this method evaluates the overall workplace without specifying the participants' qualification for each specific task. Employing IMBA on every single task is inefficient, because not every task requires a standardized characteristic.

In research, task allocation for human-robot collaboration has gained importance. In this context, a superordinated question is the definition of criteria to base the task allocation on. One way is to consider the allocation from an economic point of view, as done by Takata et al. in [3]. They evaluate tasks according to cost and time. Furthermore, their method incorporates possible changes in the overall process. Müller et al. [4] on the other hand present a process-oriented task allocation. This allocation is based on a weighted comparison between general human and robot capabilities regarding the requirements of the product and manufacturing process. Fechter et al. [5] and Ranz et al. [6] also derive the allocation based on the capabilities of the stakeholders of the HRC system. Fechter et al. only consider the capabilities of the robot and the automation of the tasks [5]. Ranz et al., on the contrary, base their allocation on the best fit between task requirements and the capabilities of the stakeholders. A disadvantage of the approaches presented in [4-6] is that general human capabilities are taken into account instead of individual ones belonging to a particular person.

These examples show that approaches for defining task allocation for HRC exist, but they are either cost-, time- or process-orientated. Furthermore, they consider only general human capabilities, which cannot be used to make a statement about the amount of assistance that an individual requires. Therefore, these approaches cannot be applied to prepare design and programming of individually adapted, inclusive HRC workplaces. This paper introduces a new approach that bases task allocation on the individual human being with their capabilities and compares them with the specific requirements of a given task. Result of this comparison is the amount of assistance, which should be provided by a collaborative robot.

The paper focuses on the description, functionality and structure of the new approach respectievly method. In Section 2, the proposed method for an individual capability-based task allocation and the determination of the amount of robotic support is explained. Section 3 discusses the results of the proposed method on the basis of an anonymized paticipant and an exemplary application. The paper is concluded in Section 4 and presents future aspects, which should be investigated in the project. 


\section{Method}

The proposed approach provides a three-step procedure. As seen in Figure 1 the three steps consist of "break down the overall task in standard processes", "evaluation of capability-based workplace requirements" and "comparison of requirement profiles with the individual capability profile" of a particular person. The following chapters will explain the mentioned steps in detail.

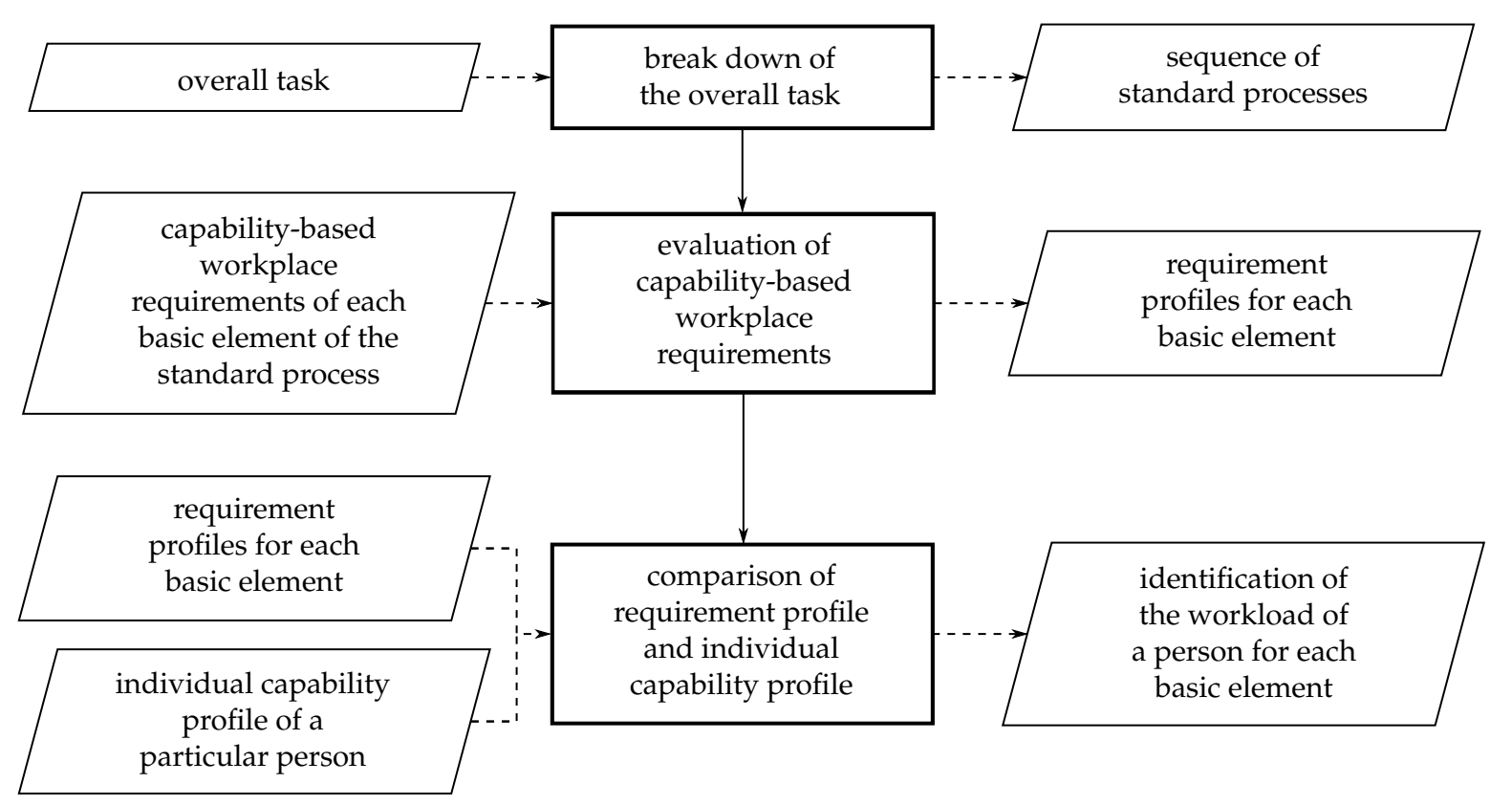

Figure 1. Overall concept of the individual capability-based task allocation.

\subsection{Break Down of Overall Task}

In comparison to existing methods such as [6], we suggest, that the break down of a process or task is composed of a process and a capability oriented scope, see Figure 2.

In the process oriented scope, the task is broken down in three levels. First level is the overall task, which a particular person has to accomplish. The second level is a sequence of standard processes that describe this overall task. These are typical processes of the value-added chain found in manufacturing, assembly, packaging and handling, like screwing or polishing. Standard processes are listed in norms such as DIN 8589-0 [7] or DIN 55405 [8] as well as other sources like Pahl et al. [9], for example.

Each standard process is defined by a particular set of basic elements. These basic elements are based on the 19 fundamental motions of Method Time Measurement (MTM) analysis representing a common approach in workflow modelling [10]. Besides the fundamental motions of MTM the following three basic elements "working with both hands", "exert a force" and "operate a device" are implemented to describe standard processes. The basic element "working with both hands" signalizes that the standard process is composed of a parallel and/or divided task requiring the use of both hands. The basic element "exert a force" describes the use of a force through fingers, hand or arm to overcome resistance without a significant movement. Therefore, it combines the fundamental motions "push" and "pull" within one element. "Operate a device" is dependent on the device that a person needs to use. Thus, the requirements for this basic element depends on the used device, respectively, tool. All in all the description of standard processes requires the fundamental motions of the hand-arm-system of MTM and the presented three basic elements, see Figure 3. 


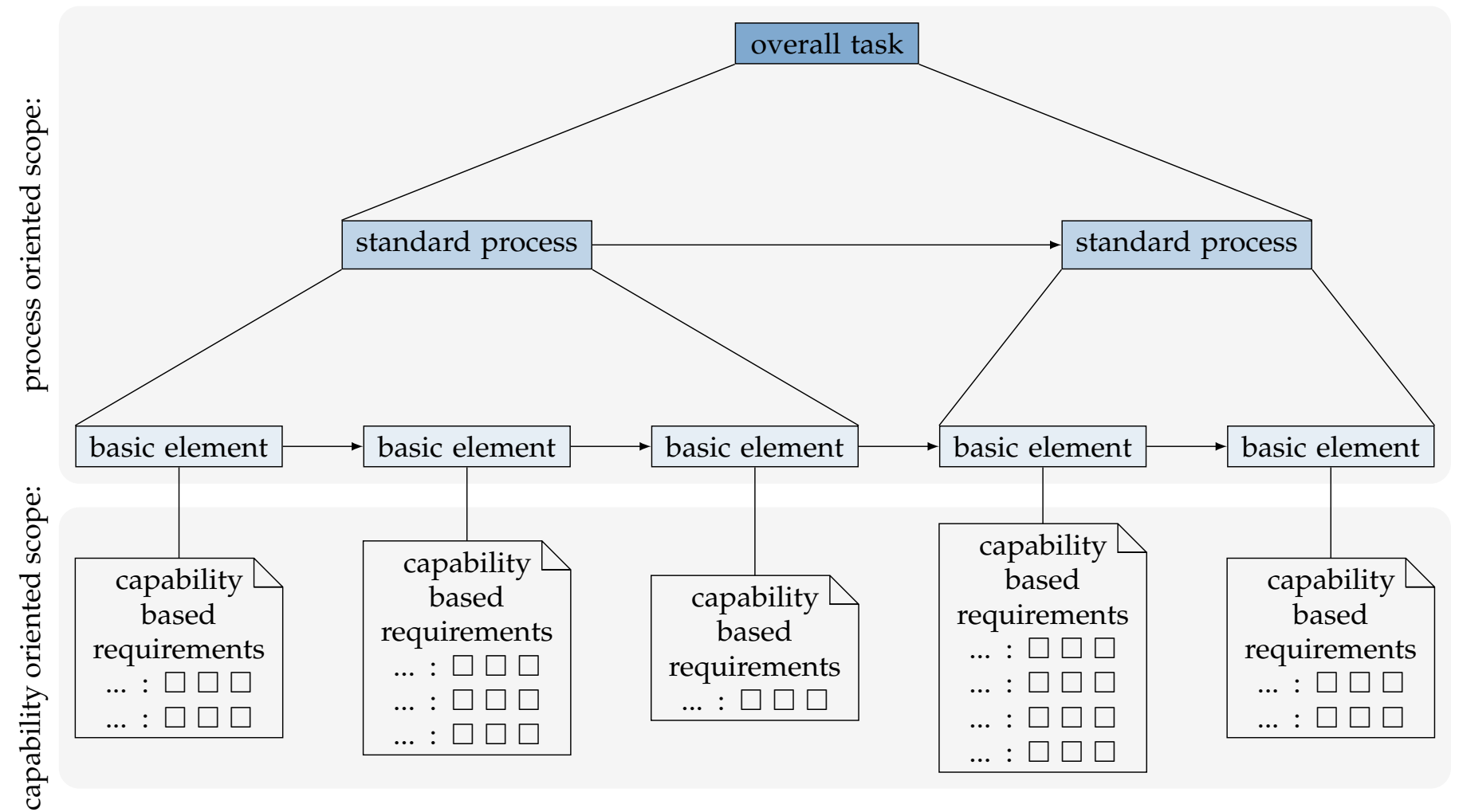

Figure 2. Concept of the break down of a process.

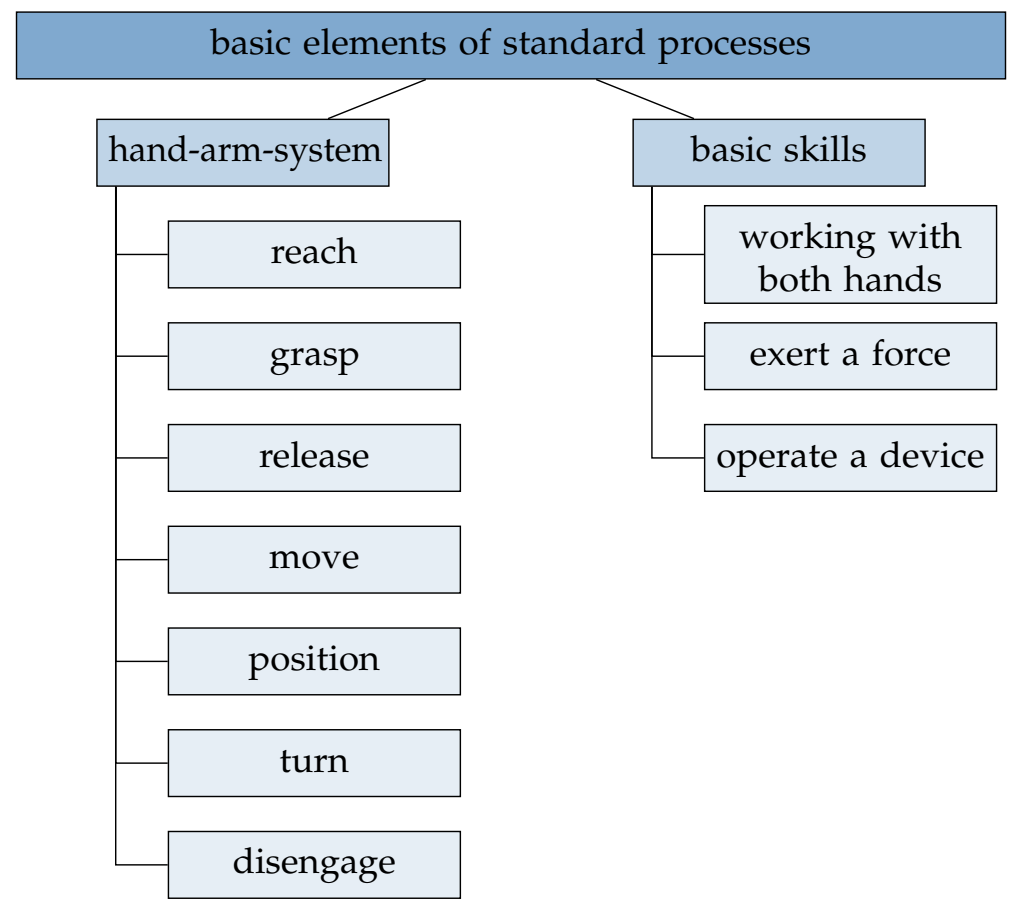

Figure 3. Basic elements of standard processes.

A specific standard process can be described by the same sequence of basic elements. Therefore, each standard process is predefined by its specific basic elements. Figure 4 exemplarily displays this break down of the standard process "form-fit positioning". 


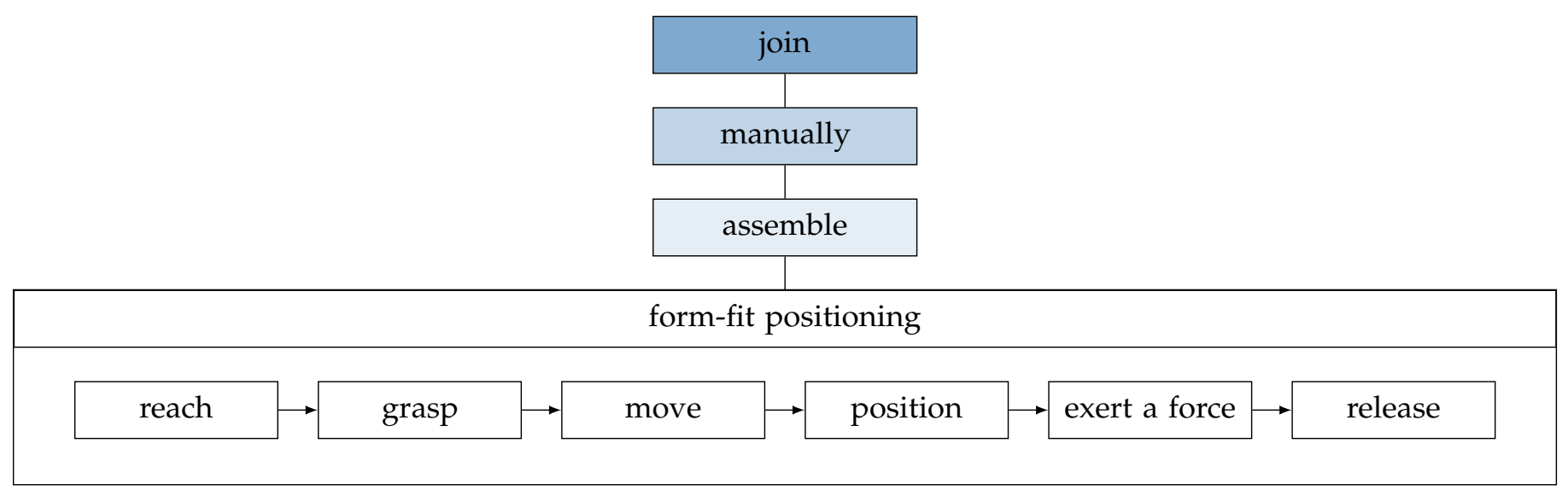

Figure 4. Break down of the standard process "form-fit positioning" in its basic elements.

Subsequent to the process analysis, the capability scope is introduced. Each basic element requires specific capabilities in order to be accomplished by a person, see Figure 2. For each basic element capability-based requirements have to be defined resulting in a requirement profile. The $I M B A$-approach lays the foundation of this profile neglecting the mental related requirements from $I M B A$, because a robot is just able to compensate physical abilities. These mental requirements belong to the categories "environmental influences", "occupational safety", "work organization" and "key skills". Furthermore, only commonly needed physical requirements of IMBA are considered for the proposed method, thus exemplarily excluding "crawling" and "climbing". Finally, the workplace requirements or abilities "arm-hand steadiness", "control precision", "multi-limb coordination", "wrist-finger speed" and "speed of limb movement" from Occupational Information Network $\left(O^{*} N E T\right)$ are added. $O^{*} N E T$ is an online database sponsored by the US Department of Labour/Employment and Training Administation (USDOL/ETA) containing occupational definitions [11]. In total around 76 capabilities are defined and available to be chosen as requirements for a basic element.

Table 1 exemplarily shows a requirement profile for the basic element "reach". In this example a person has to be able to reach forward with one arm. Additionally, the capabilities needed are standing as well as having good near and spatial vision. These requirements can vary from one overall task to another or even from one standard process to another. This is because they are dependent on circumstances in production such as cycle time, the structure of the production line and product features. The result of the break down of the overall task are requirement profiles for each basic element belonging to the chosen standard processes. 
Table 1. Example of capability-based requirements for basic element "reach" and their definitions [10-12].

\begin{tabular}{ll}
\hline REACH & $\begin{array}{l}\text { Reaching is the basic movement to move the fingers or hand to a } \\
\text { certain or undefined place. }\end{array}$ \\
\hline posture & Assume and maintain upright posture with legs stretched. \\
\hline standing & \\
\hline arm mody part movement & Reach forward with one arm. \\
\hline reach forward - one arm & \\
\hline information & $\begin{array}{l}\text { Recognize details and structures within normal reading distance } \\
\text { vision }\end{array}$ \\
\hline near vision & $\begin{array}{l}\text { Recognize objects in space in terms of shape, size and } \\
\text { arrangement. }\end{array}$ \\
\hline spatial vision & \\
\hline complex features & Move the arms quickly. \\
\hline speed of arm movement
\end{tabular}

\subsection{Evaluation and Comparison of Capability Profile and Requirement Profiles}

To determine the specific need of robot support for an individual, the determined capability-based requirements of a basic element are compared with the corresponding capabilities of this individual. In order to compare the two different types, capabilities and capability-based requirements have the same definitions and a compatible rating scale, as shown in Figure 5. It is divided in seven levels allowing sufficient differentiability to map various degrees of capabilities or workloads. Furthermore, it provides a defined center representing the average capability and workload.

very poor capability

capability X:<smiles>C1CCCCCCC1</smiles>

very low workload

capability-based requirement $\mathrm{X}$ :

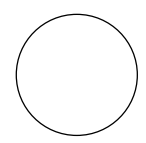

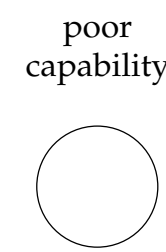
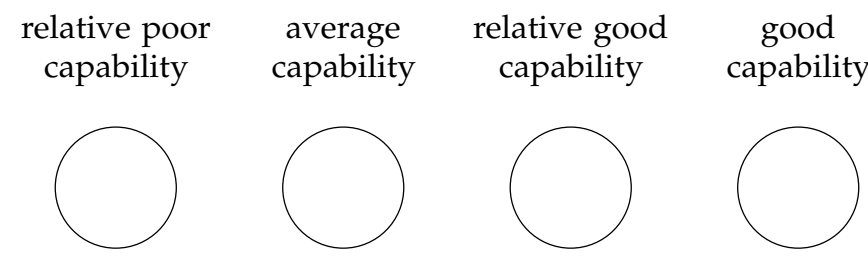

very good capability
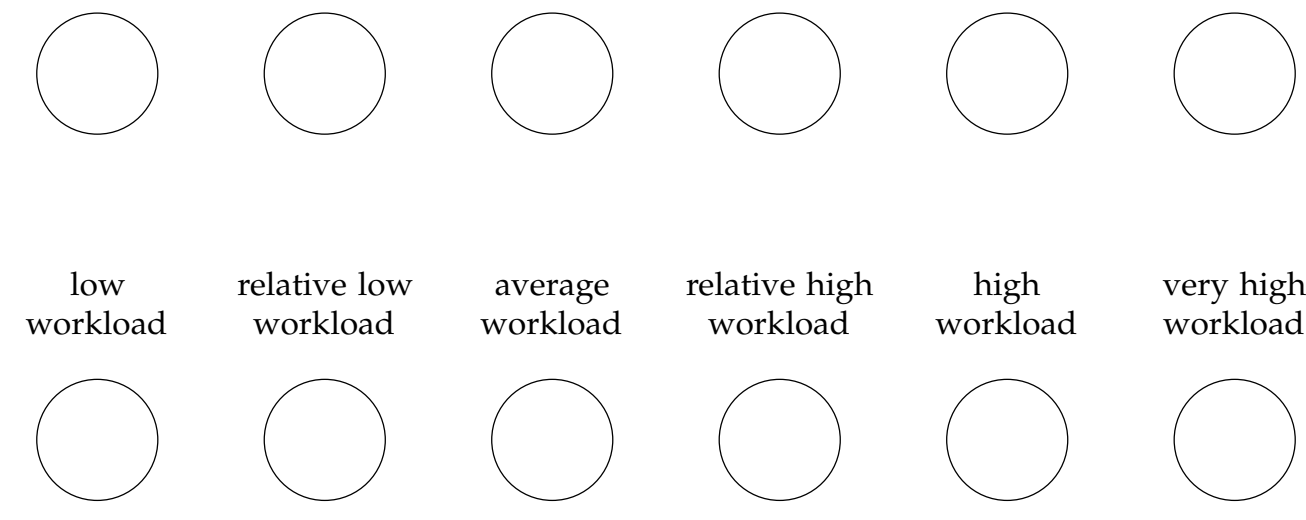

Figure 5. Rating scale for each capability, respectively, capability-based requirement.

For reasons of evaluation, the rated capability profile is referenced to the rated requirement profile of each basic element belonging to the needed standard process of the overall task. The differences between capability-related requirements and capabilities resulting from the comparison indicate an existing excessive demand and/or insufficient challenge in the evaluated characteristics. The extent of excessive demand or insufficient challenge is also returned through the comparison, as can be seen in Figures 6 and 7 . Required capabilities, in which a person is overloaded or even not challenged enough, are 
then taken into consideration for a robot assistance in the design process of the inclusive HRC workplace.

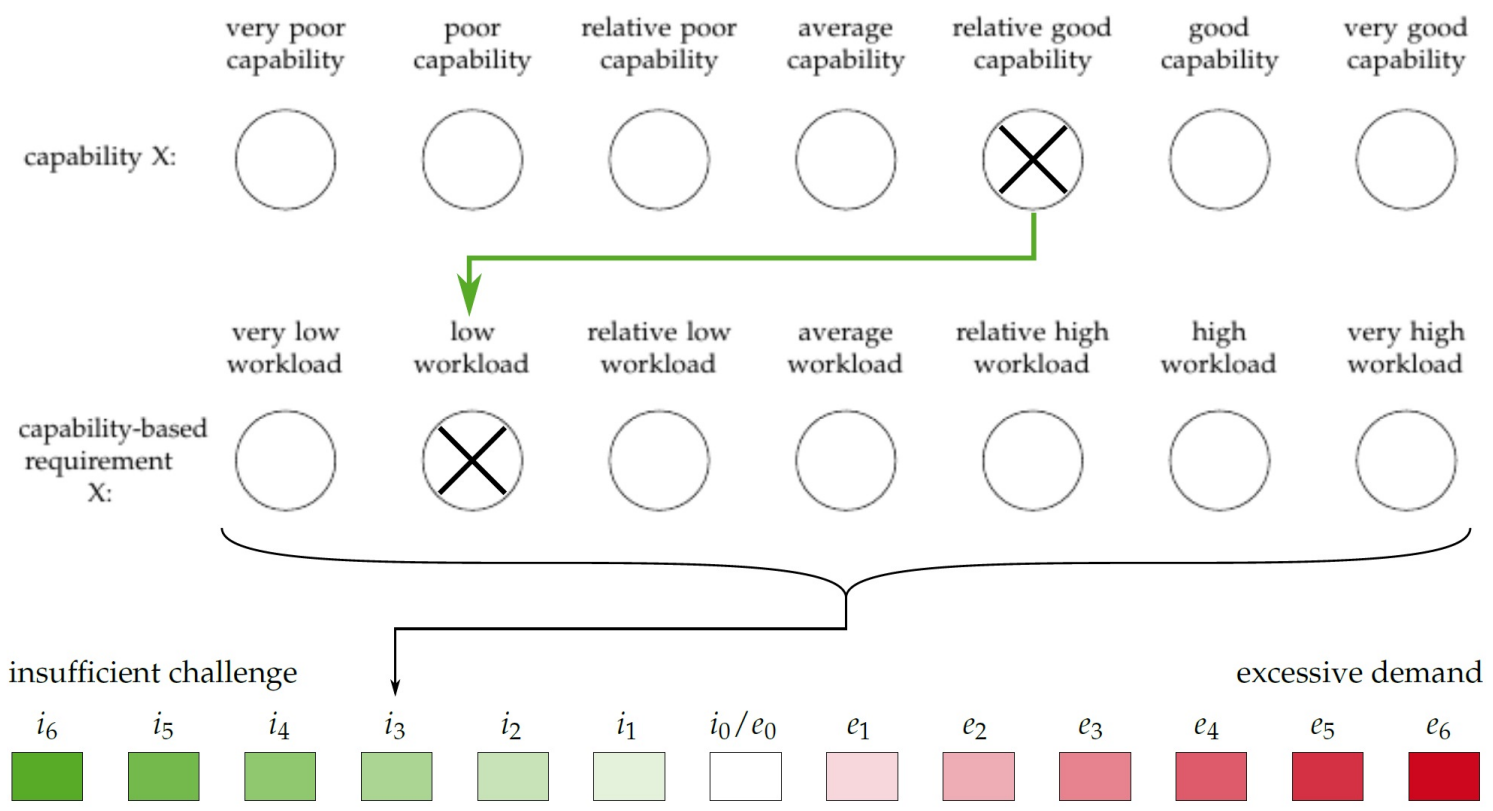

Figure 6. Evaluation: level of insufficient challenge resulting from comparison of capability and capability-based requirement.

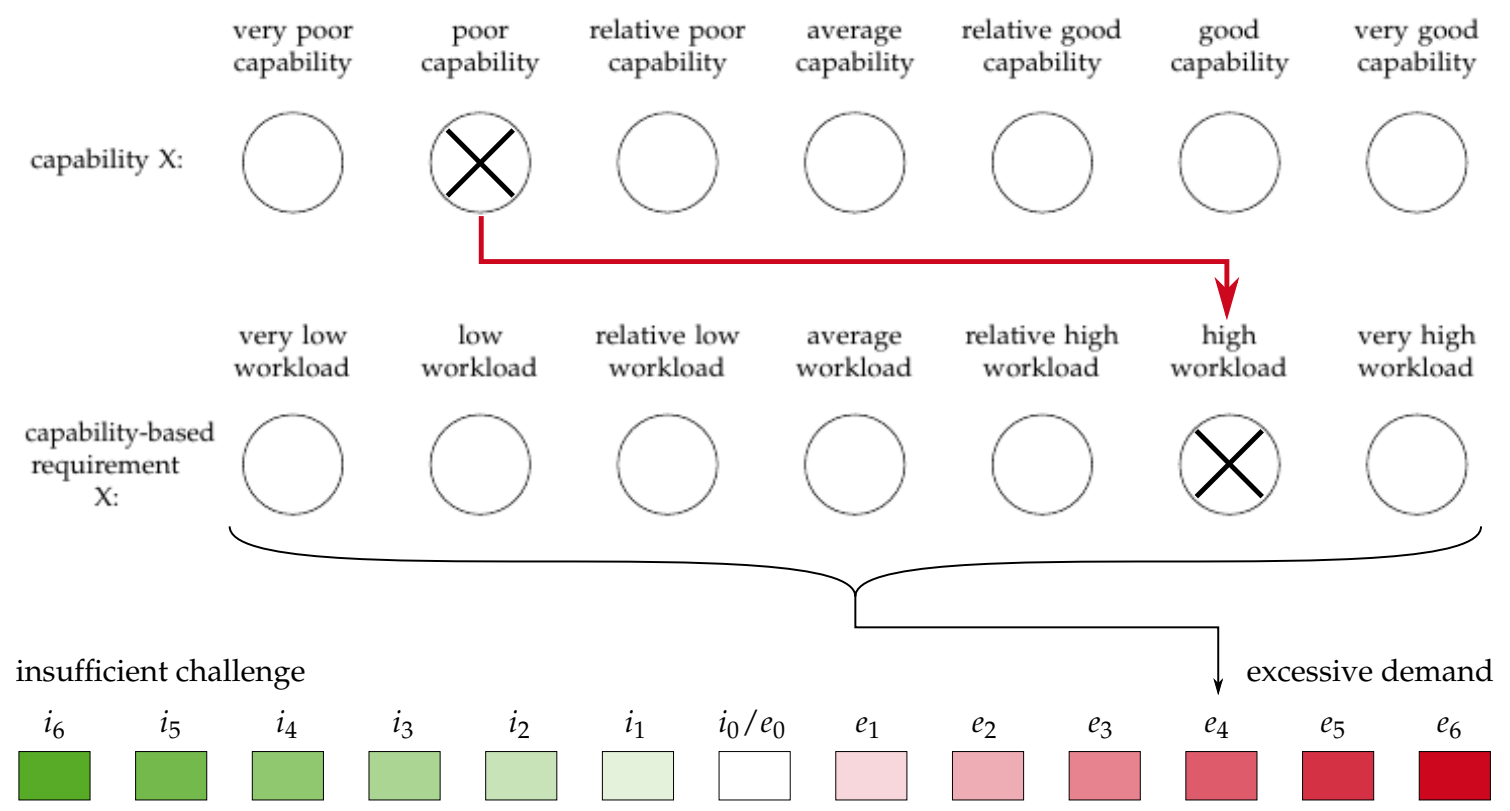

Figure 7. Evaluation: level of excessive demand resulting from comparison of capability and capability-based requirement.

\section{Results and Discussion}

The results of the method presented are discussed on the basis of an exemplary application provided by an industrial company and on the basis of an individual skill profile of an anonymized participant. Finally, the concept of the human-robot workplace derived from this is presented, see Figure 8.

During the task, metal sheets must be inserted into a fixture to load a resistance welding machine. The standard process "form-fit positioning" is part of the overall task and is already shown in Figure 4. Thus, the required basic elements are defined.

The profile comparison with the individual capability profile of the participant shows, 
that the person cannot stand due to its disability and is therefore strongly overstrained. In this case, a robot assistance system cannot reduce the overload for obvious reasons. Accordingly, a height-adjustable workplace is necessary to enable the participant in a wheelchair to perform the task. In addition, the participant is overloaded with the task of "reaching forward". This is required for the basic elements "reach out" and "bring". In this case, the assistance of a robot capable of HRC is needed to overcome the high workload of the participant.

The requirements "near vision" and "spatial vision", which are necessary for all capabilities of the standard process "form-fit positioning" excluding "exert a force", are sufficiently fulfilled by the participant, resulting in an average workload. Therefore, no support is required. Noteworthy is that most of the participants have sufficient vision capabilities. This is why, visual quality checks on produced parts should be considered as additional tasks alongside the assembly tasks.

Finally, the requirements that cause the participant to be under challenged are listed. These mostly include one-sided "hand grip" and "finger grip" and are needed for all basic elements except "reach". Requirements, in which a person is insufficiently challenged, have to be evaluated individually. In these cases, a collaborative robot could be used as an assistive device. The level of insufficient challenge and mental state of an individual is crucial. A requirement that is insufficiently challenging physically could still be difficult mentally. Basis for this decision is always self-actualization and satisfaction of the individual. At the moment, capability- based requirements, in which the person is insufficiently challenged, are planned to be executed by the participant. The results of the profile comparison for the standard process "form-fit positioning" are summarized in Figure 8.
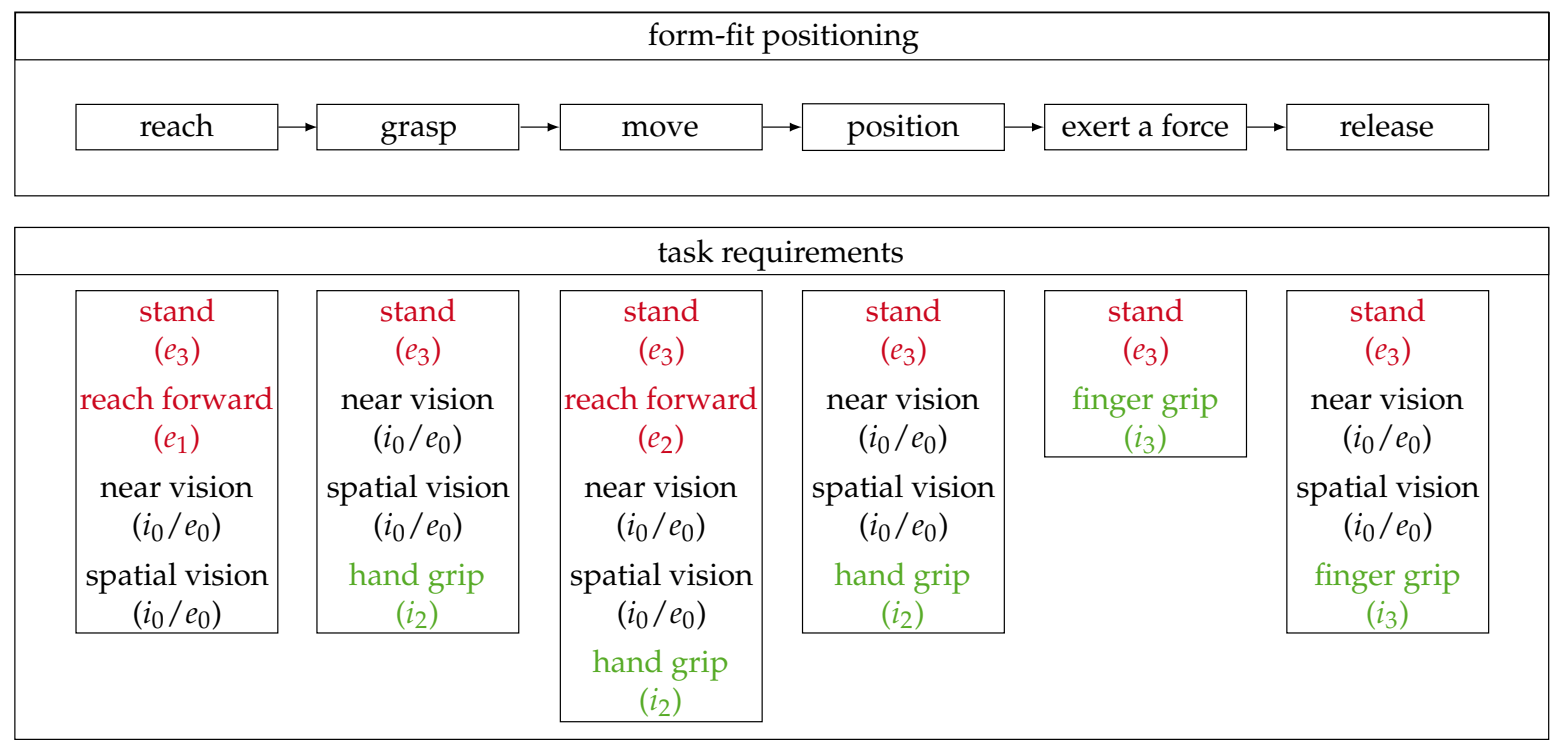

Figure 8. Summary of comparison subdivided into overloaded (red), average workload (black) and under challenged (green).

In addition to the listed requirements, the workplace should be designed in such a way that many different assembly and testing processes can be represented, which are found in industrial applications. Furthermore, the principles of ergonomics should be implemented in the design. For this reason, the present concept results in a workplace based on a typical assembly station consisting of a height-adjustable table, a monitor and lighting as well as fixed places for tools, materials and end products. The participant and the HRC capable robot must have access to tools, materials and storage of the final products. Additionally, a mobile platform can assist by supplying materials to the workplace. The concept is shown in Figure 9. 


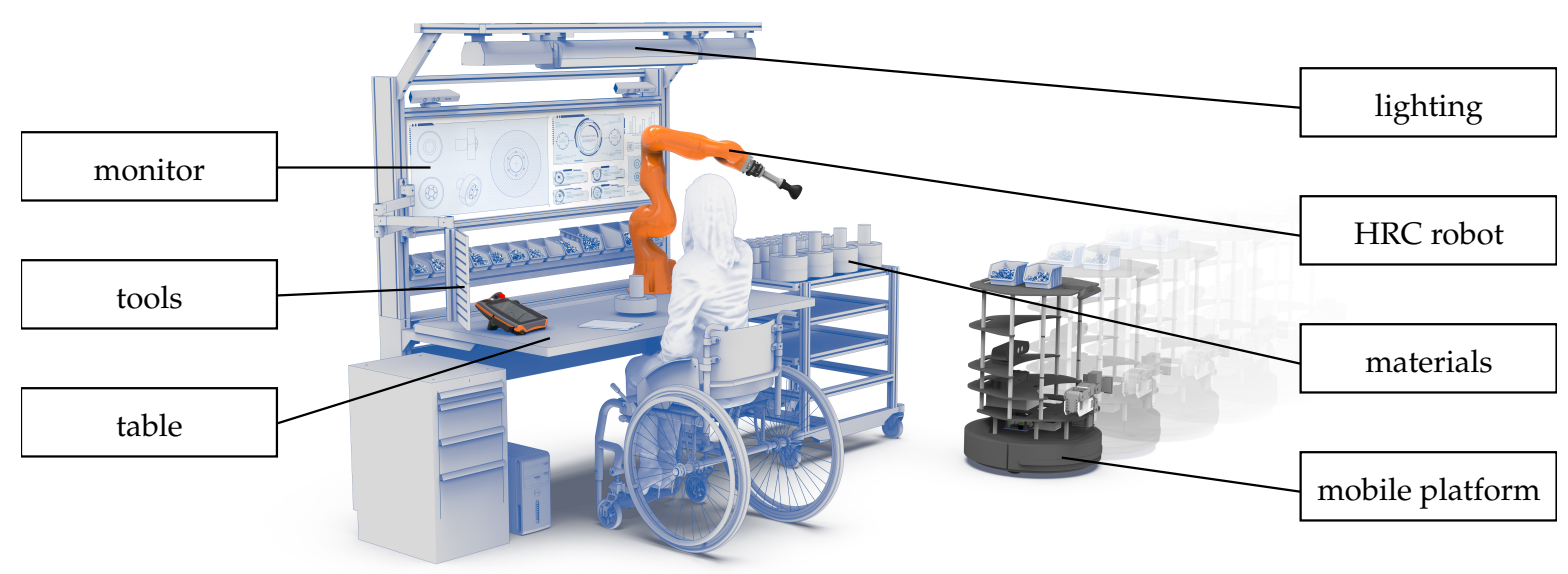

Figure 9. Concept of human-robot workplace for people with disabilities.

\section{Conclusions}

This paper introduces a novel method for task allocation between people with physical disabillities and collaborative robots. It determines the amount of assistance that an individual requires to fullfill a given task. Robotic assistance is needed whenever a participant is either insufficiently challenged or excessivly demanded. In comparison to similar approaches, this method respects the individual capabilities of a human being and compares them to the specific requirements of a given process. The result is an amount of assistance, which should be provided by the robot for each process requirement. Additionally, this paper presents the concept of an inclusive workplace, which is ergonomically adjustable and accessible to disabled people.

Future work of this project includes the final design and setup of the human-robot workplace for conducting industrial test scenarios based on the shown concept. Furthermore, the programming of the robot has to meet the individual capability profiles of the participant demanding intuitive and modular operation by the participants. When and how much robotic assistance is needed depends on the particular amount of insufficient challenge or excessive demand and remains to be investigated in this project. Based on the individual capabilities, the robot program has to account for different levels of assistance varying between no assistance and full automation. In addition, an unskilled actor must program the workplace for a new individual or task. This results in high requirements on the operability of the workstation and the robotic programm.

Finally, the new method for task allocation has to be validated on more participants and different industrial tasks.

Author Contributions: Writing-original draft preparation, E.H. and C.W.; writing-review and editing, M.L.; supervision, B.C. and M.H. All authors have read and agreed to the published version of the manuscript.

Funding: This research was funded by Stiftung Wohlfahrtspflege NRW, Landschaftsverband Rheinland and Caritasverband für die Stadt Köln e.V.

Institutional Review Board Statement: Not applicable.

Informed Consent Statement: Not applicable.

Data Availability Statement: Not applicable.

Acknowledgments: Caritas Wertarbeit and Fachhochschule des Mittelstands GmbH.

Conflicts of Interest: The authors declare no conflict of interest. The funders had no role in the design of the study; in the collection, analyses, or interpretation of data; in the writing of the manuscript, or in the decision to publish the results. 


\begin{abstract}
Abbreviations
The following abbreviations are used in this manuscript:

MDPI Multidisciplinary Digital Publishing Institute

HRC Human-Robot Collaboration

IMBA Integration of People with Disabilities into the Working World

MTM Method Time Measurement
\end{abstract}

\title{
References
}

1. Fitts, P.M. (Ed.) Human Engineering for an Effective Air Navigation and Control System; National Research Council: Washington, DC, USA, 1951.

2. IMBA Introduction. Available online: http://www.imba.de/documents/einfuehrungenglisch.pdf (accessed on 24 November 2020).

3. Takata, S.; Hirano, T. Human and Robot Allocation Method for Hybrid Assembly Systems. CIRP Ann. 2011, 60, 9-12. [CrossRef]

4. Müller, R.; Vette, M.; Mailahn, O. Process-oriented Task Assignment for Assembly Processes with Human-robot Interaction. Procedia CIRP 2016, 44, 210-215. [CrossRef]

5. Fechter, M.; Foith-Förster, P.; Pfeiffer, M.S.; Bauernhansl, T. Axiomatic Design Approach for Human-robot Collaboration in Flexibly Linked Assembly Layouts. Procedia CIRP 2016, 50, 629-634. [CrossRef]

6. Ranz, F.; Hummel, V.; Sihn, W. Capability-based Task Allocation in Human-robot Collaboration. Procedia Manuf. 2017, 9, 182-189. [CrossRef]

7. Deutsches Institut für Normung e.V. DIN 8589-0:2003-09, Fertigungsverfahren Spanen—Teil 0: Allgemeines; Einordnung, Unterteilung, Begriffe; Beuth Verlag GmbH: Berlin, Germany, 2003. [CrossRef]

8. Deutsches Institut für Normung e.V. DIN 55405:2014-12, Verpackung_Terminologie—Begriffe; Beuth Verlag GmbH: Berlin, Germany, 2014. [CrossRef]

9. Pahl, G.; Beitz, W.; Feldhusen, J.; Grote, K.H. Engineering Design: A Systematic Approach; Springer: Berlin, Germany, 2007; doi:10.1007/978-1-84628-319-2. [CrossRef]

10. Bokranz, R.; Landau, K. Produktivitätsmanagement von Arbeitssystemen: MTM-Handbuch; Schäffer-Poeschel: Stuttgart, Germany, 2006; ISBN: 978-3-7910-2133-1.

11. Instructions for Making Abilities Ratings. Available online: https://www.onetcenter.org/dl_files/MS_Word/Abilities.pdf (accessed on 24 November 2020).

12. Bundesministerium für Gesundheit und Soziale Sicherung. (Ed.) IMBA. Das Instrument Für den Fähigkeits-Gerechten Personaleinsatz. Definitionen, 3rd ed.; IMBA: Boulder, CO, USA, 2015. 